\title{
Impact of health capital on economic growth in Singapore: an ARDL approach to cointegration
}

\begin{abstract}
Purpose: The purpose of this paper is to analyze the long-term impacts of health capital on economic growth in Singapore from 1980 to 2013. Design/methodology/approach: Auto regressive distributed lag (ARDL)-ECM methodology and several diagnostic and specification tests were used to estimate the impact of health capital on economic growth on time series data covering the period 1980-2013. Findings: The results confirm that health capital (measure by health expenditure per capita) positively and significantly affects Singapore's economic growth in the long run. In addition, the equilibrium error correction coefficient lagged by one in the short-run is approximately 83.25 percent for all estimated variables, implying a considerably high speed of long-term adjustment to equilibrium following a short-term shock. Moreover, the Toda-Yamamoto's Granger causality estimation reveals that there is a unidirectional causality from health expenditure per capita to GDP per capita. Research limitations/implications: The finding simply that Singapore's economic growth could be improved significantly if expenditure on health capital is increased. This eventually would have a substantial impact on human productivity which leads to improved output per capita. Thus, policy makers and/or the government should strive to create institutional capacity to improve basic health service by strengthening the health institutions infrastructure that produces healthy and quality manpower. Originality/value: Grounded on the premises that there are little or no studies on the impact of health capital on Singapore economy, this paper provides new evidence on the potential effect of health capital on Singapore's economic growth over the last three decades. Also, this study explore the causal effect (unidirectional or bidirectional) between health capital and economic growth.
\end{abstract}

Keyword: Singapore; Economic growth; Autoregressive distributed lag; Health capital 